\title{
Ileus Caused by Large Diverticulum of Postbulbar Duodenum: Case Report
}

\author{
Grgić Dora1, Zovak Mario², Brkić Marina33, Brkić Tomislav³ \\ ${ }^{1}$ Division of Gastroenterology and Hepatology, Department of Internal Medicine, University Hospital Rebro, \\ Zagreb, Croatia \\ ${ }^{2}$ Clinic of Surgery, University Hospital Sestre Milosrdnice, Zagreb, Croatia \\ ${ }^{3}$ Apnea Diagnostic Clinic of Internal Medicine, Neurology and Anesthesiology, Reanimation and Intensive Care, \\ Zagreb, Croatia \\ Email: dora.grgic1@gmail.com
}

Received 28 May 2015; accepted 1 September 2015; published 4 September 2015

Copyright (C) 2015 by authors and Scientific Research Publishing Inc.

This work is licensed under the Creative Commons Attribution International License (CC BY).

http://creativecommons.org/licenses/by/4.0/

cc) (i) Open Access

\begin{abstract}
Duodenal diverticula are common and are usually found in patients undergoing roentgenographic investigation of the upper gastrointestinal tract. The majority of these cases are asymptomatic and rarely require operative intervention. Occasionally they can result in the obstruction of the biliary and/or pancreatic ducts, haemorrhage or perforation. Symptomiatic cases may require endoscopic or surgical intervention. Herein, we present a case report of a female patient who underwent surgical procedure due to repetitive obstructive symptoms.
\end{abstract}

\section{Keywords}

Duodenal Diverticulum, Obstruction, Upper Endoscopy, Diverticulectomy

\section{Introduction}

Duodenal diverticula occur very commonly in upper gastrointestinal barium studies, but despite their incidence duodenal diverticula are rarely symptomatic [1] [2]. For that reason, the duodenum is usually overlooked as an underlying cause of acute abdomen [3]. That is why we present a case of symptomatic large duodenal diverticulum in a patient who presented with an upper intestinal obstruction.

\section{Case Report}

A 47-year-old woman was admitted to a hospital in November 2014 with symptoms of upper abdominal pain, nausea and vomiting. On admission, plain film of the abdomen was normal but barium study revealed huge di-

How to cite this paper: Dora, G., Mario, Z., Marina, B. and Tomislav, B. (2015) Ileus Caused by Large Diverticulum of Postbulbar Duodenum: Case Report. Open Journal of Gastroenterology, 5, 115-118.

http://dx.doi.org/10.4236/ojgas.2015.59019 
verticulum with diameter of cca $60 \times 40 \mathrm{~mm}$ nearby bulbi duodeni (Figure 1). Her past medical history was significant for symptoms of obstruction since her youth. So far, she was admitted to hospital with ileus many times. She also had family history of ulcer disease and colorectal carcinoma. In her 21-st year she had left adnexetomy due to ovarian cyst. The patient was dismissed from hospital after termination of symptoms and was sent to gastroenterological workup.

Abdominal ultrasound showed large diverticulum next to hepatoduodenal ligamentum, with clear signs of disorders of passage in pars descedens duodeni. The rest of abdominal ultrasound was normal. The patient was sent to endoscopy as preoperative workup (it was necessary to distinguish between papila Vateri and diverticulum). Upper endoscopy revealed in postbulbar segment beneath papila Vateri diverticulum with dimensions cca $60 \times 40 \mathrm{~mm}$. Under diverticulum, next to crossing to jejunum, duodenum was rotataed around its axis (torsion around ligamentum Treitz) (Figure 2). Lower endoscopy was normal, except significant dolichocolon. Due to endoscopy finding, the patient was sent back to abdominal surgeon to perform operation.

The patient was operated in March 2015. Median laparotomy and diverticulectomy were performed (Figure 3). The postoperative course went without complications. The patient remained hospitalized for 14 days with local surgical wound healing, as well as changes in her diet with food supplements. Control gastrographin study was made on the 7th postoperative day and no extravasation of contrast was found (Figure 4). The patient was dismissed from hospital on the 14th postoperative day. On control examination the patient was asymptomatic and in very good condition, without feeling any discomfort after surgical intervention.

\section{Discussion}

A diverticulum is an abnormal sac or pouch protruding from the wall of a hollow organ [1] [4]. Diverticular disease of the small intestine is relatively common. The prevalence of small intestinal diverticula ranges from
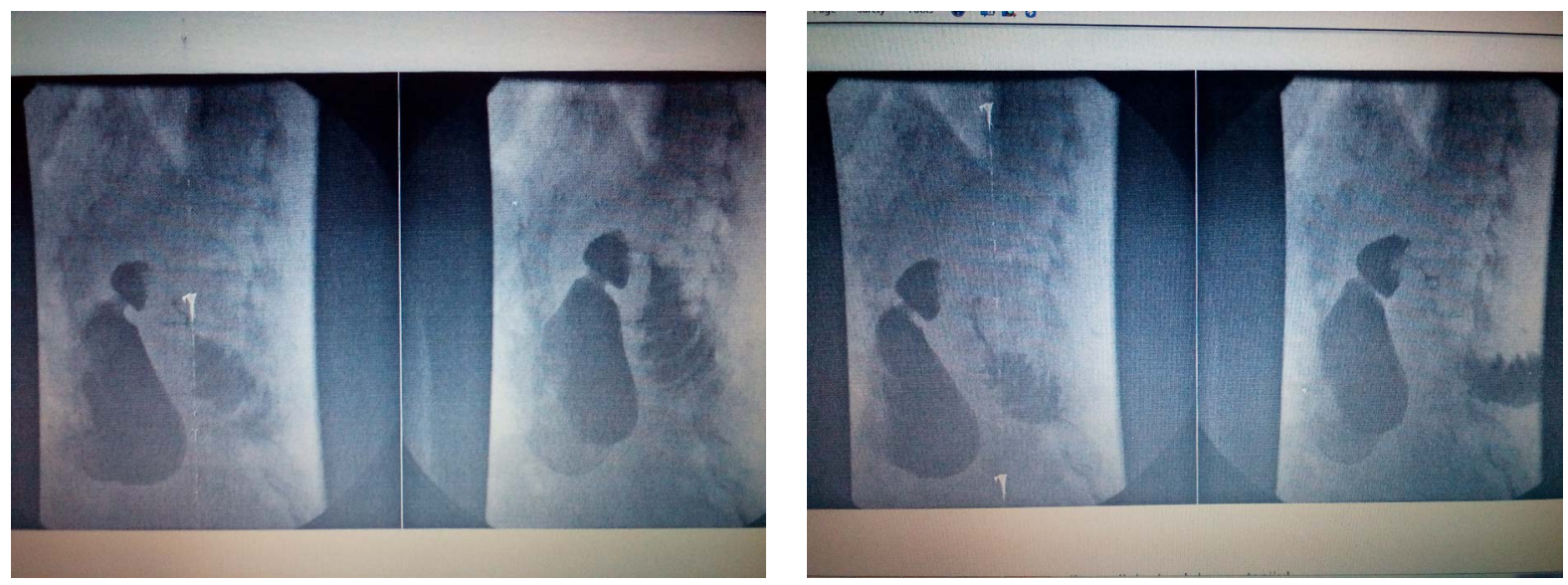

Figure 1. Barium study before surgery. It shows diverticulum cca $2.5 \times 2.5 \mathrm{~cm}$ in descedent part of duodenum.

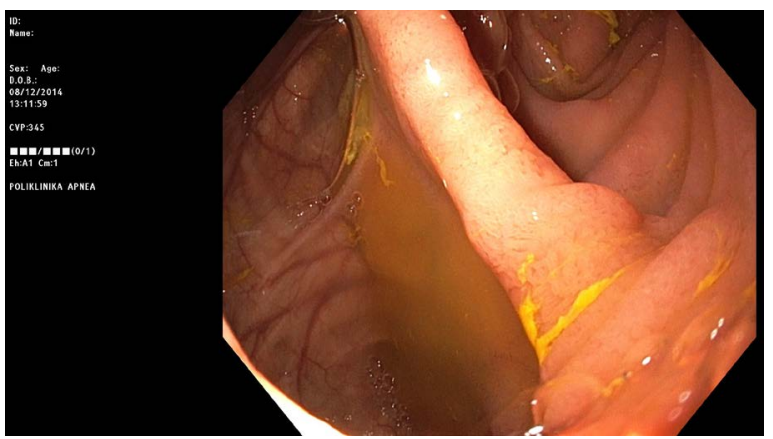

(a)

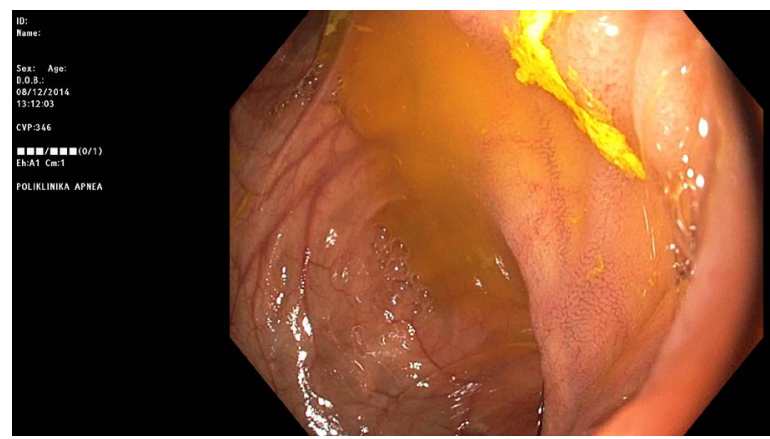

(b)

Figure 2. (a) Upper endoscopy shows an opening of large diverticulum in descedent part of duodenum; (b) Upper endoscopy showing pars descedens duodeni and opening of diverticulum. 


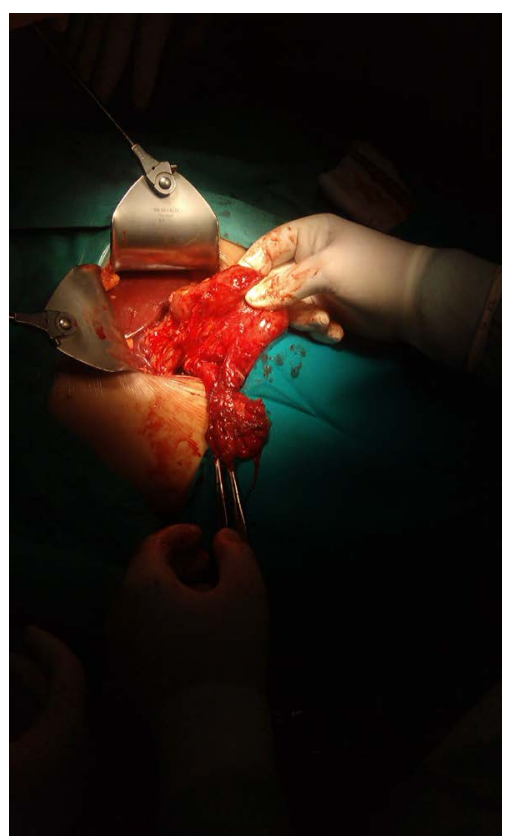

(a)

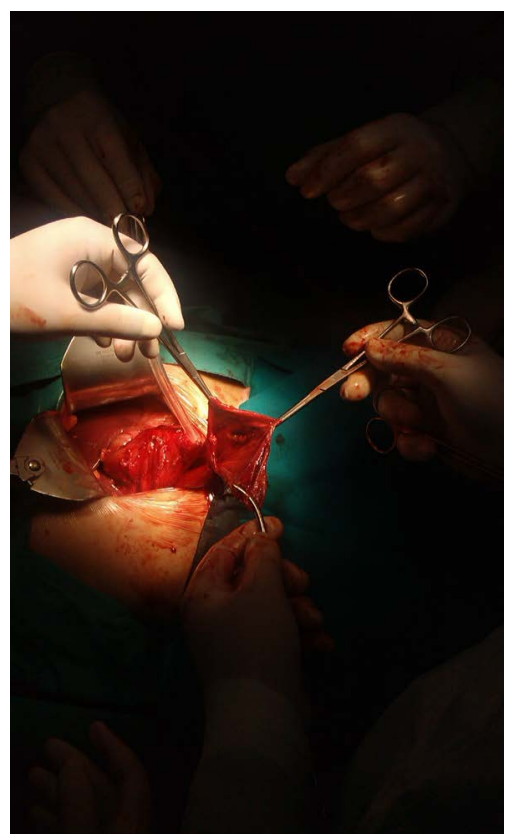

(b)

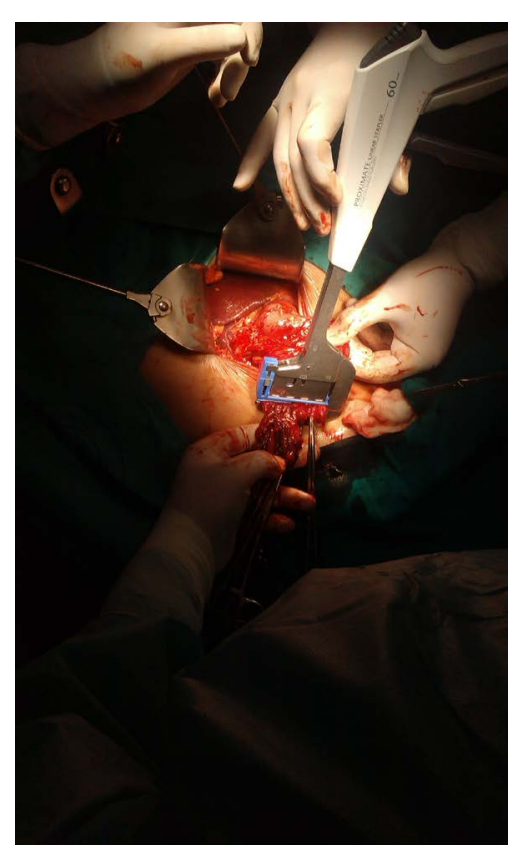

(c)

Figure 3. (a) Surgery large diverticulum that is going to be resected; (b) Diverticulum; (c) Resection of dicerticulum.
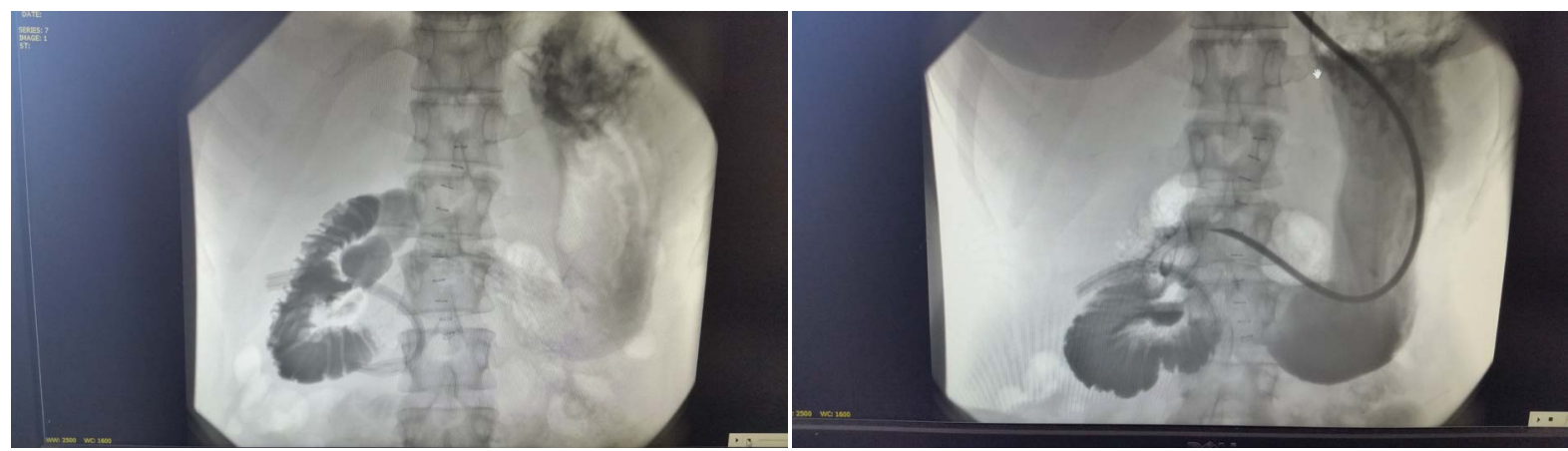

Figure 4. Gastrographin study after surgery.

$0.06 \%$ to $1.3 \%$. The etiopathogenesis is unclear, although the current hypothesis focuses on abnormalities in the smooth muscle or myenteric plexus, on intestinal dyskinesis and on high intraluminal pressures [5]. Duodenal diverticula are the most common acquired diverticula of the small bowel, and Meckel's divericulum is the most common true congenital diverticulum of the small bowel. Duodenal diverticula represent the second most common site for diverticulum formation after the colon [1] [6]-[8]. They occur twice as often in women as in men and are rare in patients younger than age 40. Two thirds to three fourths of duodenal diverticula are found in the periampullary region. The overwhelming majority of duodenal diverticula are asymptomatic and are usually noted incidentally by an upper gastrointestinal series [5] [9]. Complications are rare and perforation was only reported in less than 200 cases [6]. Diagnosis may also be obtained by upper gastrointestinal endoscopy. Less than $5 \%$ of duodenal diverticula will require surgery due to complication of the diverticulum itself.

The causes of small bowel obstruction can be divided into three categories: 1) Obstruction arising from extraluminal causes (adhesions, hernias, etc.); 2) Obstruction intrinsic to the bowel wall (primary tumors); 3) Intraluminal obturator obstruction (gallstones, foreign bodies etc.). Adhesions secondary to previous surgery are by far the most common cause of small bowel obstruction. The cardinal symptoms of intestinal obstruction include colicky abdominal pain, nausea, vomiting, abdominal distension, and a failure to pass flatus and feces. These symptoms may vary regarding the site and duration of obstruction. Nausea and vomiting are more common with a higher obstruction and may be the only symptoms in patients with high intestinal obstruction [1] [6]. 
The diagnosis of intestinal obstruction is often immediately evident after a thorough history and physical examination. Plain radiographs usually confirm the clinical suspicion and define more accurately the site of obstruction. The accuracy of diagnosis of the small intestinal obstruction on plain abdominal radiographs is estimated to be approximately $60 \%$.

Barium studies have been a useful adjunct in certain patients with a presumed obstruction. Barium studies can precisely demonstrate the level of the obstruction as well as the cause of the obstruction in certain instances. Also, barium studies are recommended in patients with a history of recurring obstruction or low-grade mechanical obstruction to precisely define the obstructed segment and degree of obstruction.

Several operative procedures have been described for the treatment of the symptomatic duodenal diverticulum. The most common and the most effective treatment is diverticulectomy which is most easily accomplished by performing a wide Kocher maneuver that exposes the duodenum. The diverticulum is then excised, and the duodenum is closed in a transverse or longitudinal fashion, whichever produces the least amount of luminal obstruction. Due to the close proximity of the ampulla, careful identification of the ampulla is essential to prevent injury to the common bile duct and the pancreatic duct. The main postoperative complication of diverticulectomy is duodenal leak or fistula, which carries up to a $30 \%$ mortality rate [7].

Not many case reports with symtomatic duodenal diverticula were published. Usually most common complication described was perforation when segmental duodenectomy was performed. Other complications mentioned were gastrointestinal bleeding, intractable pain, biliary or pancreatic obstruction and gastrointestinal obstruction [1] [6]. In most papers, authors concluded that operative treatment of duodenal diverticula is safe but should be reserved for those with emergent presentations [2] [6] [8] [10]. Moreover, few papers emphasised the need for better diagnostic evaluation of upper gastrointestinal diverticula, as they are mostly unrecognized [8].

\section{Conclusion}

It is important to think of duodenal divericula as a cause of acute abdomen, as duodenal diverticula are not so rare. Upper endoscopy and upper gastrointestinal radiographic imaging should be obtained in diagnostic pathway. Surgical resection remains the mainstray of treatment when diverticulum is large, symptomatic or complicated by perforation, volvulus or bleeding.

\section{References}

[1] Sabiston Textbook of Surgery, 17th Edition, 1335-1339, 1363-1364.

[2] Mathis, K.L. and Farley, D.R. (2007) Operative Management of Symptomatic Duodenal Diverticula. American Journal of Surgery, 193, 305-308. http://dx.doi.org/10.1016/j.amjsurg.2006.09.024

[3] Perdikakis, E., Chryssou, E.G. and Karantanas, A. (2011) Diagnosis of Periampullary Duodenal Diverticula: The Value of New Imaging Techniques. Annals of Gastroenterology, 24, 192-199.

[4] Ferreira-Aparicio, F.E., Gutierrez-Vega, R., Galvez-Molina, Y., Ontiveros-Nevares, P., Athie-Gutierrez, C. and Montalvo-Jave, E.E. (2012) Diverticular Disease of the Small Bowel. Case Reports in Gastroenterology, 6, 668-676. http://dx.doi.org/10.1159/000343598

[5] Kassir, R., Boueil-Bourlier, A., Baccot, S., et al. (2015) Jejuno-Ileal Diverticulitis: Etiopathogenicity, Diagnosis and Management. International Journal of Surgery Case Reports, 10, 151-153. http://dx.doi.org/10.1016/j.ijscr.2015.03.044

[6] Costa Simões, V., Santos, B., Magalhães, S., Faria, G., Sousa Silva, D. and Davide, J. (2014) Perforated Duodenal Diverticulum: Surgical Treatment and Literature Review. International Journal of Surgery Case Reports, 5, 547-550. http://dx.doi.org/10.1016/j.ijscr.2014.06.008

[7] Oukachbi, N. and Brouzes, S. (2013) Management of Complicated Duodenal Diverticula. Journal of Vascular Surgery, 150, 173-179. http://dx.doi.org/10.1016/j.jviscsurg.2013.04.006

[8] Guardado-Bermudez, F., Ardisson-Zamora, F.J., Rojas-Gonzales, J.D., Medina-Benitez, A. and Corona-Suarez, F. (2013) Perforated Duodenal Diverticula. Case Report and Treatment Options. Cir Cir, 81, 340-347.

[9] Brzost-Andersen, B. and Amstrup, J.H. (1997) Duodenal Divericula. Ugeskr Laeger, 159, 4504-4507.

[10] Rossetti, A., Buchs, N.C., Bucher, P., Dominguez, S. and Morel, P. (2013) Perforated Duodenal Diverticulum, a Rare Complication of a Common Pathology: A Seven-Patient Case Series. World Journal of Gastrointestinal Surgery, 5, 47-50. http://dx.doi.org/10.4240/wigs.v5.i3.47 